\title{
Seeking the "Beauty Center" in the Brain: A Meta-Analysis of fMRI Studies of Beautiful Human Faces and Visual Art
}

\author{
Hu Chuan-Peng ${ }^{1,2}$ (D) $\cdot$ Yi Huang ${ }^{1,3} \cdot$ Simon B. Eickhoff ${ }^{4,5} \cdot$ Kaiping Peng $^{1} \cdot$ Jie Sui $^{6}$
}

Accepted: 28 August 2020 / Published online: 21 October 2020

(C) The Psychonomic Society, Inc. 2020

\begin{abstract}
During the past two decades, cognitive neuroscientists have sought to elucidate the common neural basis of the experience of beauty. Still, empirical evidence for such common neural basis of different forms of beauty is not conclusive. To address this question, we performed an activation likelihood estimation (ALE) meta-analysis on the existing neuroimaging studies of beauty appreciation of faces and visual art by nonexpert adults (49 studies, 982 participants, meta-data are available at https://osf.io/ s9xds/). We observed that perceiving these two forms of beauty activated distinct brain regions: While the beauty of faces convergently activated the left ventral striatum, the beauty of visual art convergently activated the anterior medial prefrontal cortex (aMPFC). However, a conjunction analysis failed to reveal any common brain regions for the beauty of visual art and faces. The implications of these results are discussed.
\end{abstract}

Keywords Beauty $\cdot$ Faces $\cdot$ Visual art $\cdot$ Functional magnetic resonance imaging $\cdot$ Activation likelihood estimation

\section{Introduction}

The nature of beauty is a long-standing question in many disciplines. A critical issue from psychologists and neuroscientists is whether there is a common neural basis representing different forms of beauty in the brain. Researchers have

We embrace the values of openness and transparency in science and will furthermore publish all data (raw and processed) necessary to reproduce the reported results in this manuscript (see https://osf.io/s9xds/).

Electronic supplementary material The online version of this article (https://doi.org/10.3758/s13415-020-00827-z) contains supplementary material, which is available to authorized users.

Hu Chuan-Peng

hcp4715@gmail.com

1 Department of Psychology, Tsinghua University, Beijing, People's Republic of China

2 Leibniz Institute for Resilience Research (LIR), Mainz, Germany

3 School of Business and Management, Shanghai International Studies University, Shanghai, People's Republic of China

4 Institute of Systems Neuroscience, Medical Faculty, Heinrich Heine University Düsseldorf, Düsseldorf, Germany

5 Institute of Neuroscience and Medicine, Brain \& Behaviour (INM-7), Research Centre Jülich, Jülich, Germany

6 School of Psychology, the University of Aberdeen, Aberdeen, UK attempted to investigate this issue using experimental approaches to assessing aesthetic responses to beauty while brain activities were recorded (Aharon et al., 2001; Chatterjee \& Vartanian, 2014; Pearce et al., 2016). Almost two decades have passed. There is still no consensus about whether there is a unique brain representation specific to beauty (Conway \& Rehding, 2013; Ishizu \& Zeki, 2011; Skov \& Nadal, 2020). Inconsistent findings across studies might suggest that there are beautify form-specific modules in the brain. The discrepant results also might reflect variations of tasks and relevant parameters used in these studies, although there might be a common beauty-representation in the brain. One way to examine these two views is to conduct meta-analysis by synthesizing the empirical neuroimaging studies in the field. This was conducted here by using activation likelihood estimation (ALE) meta-analyses, which focused on studies that examined the experience of beauty. ${ }^{1}$

From the computational view of cognition (Marr, 1982/ 2010), understanding how beauty is experienced in humans may need different level analyses: implementational level, algorithmic-representational level, and computational level. As pointed out by Pearce et al. (2016), brain imaging studies mainly address the implementation level and less on

\footnotetext{
${ }^{1}$ Note that the present study focused on the experience of beauty instead of a broad aesthetic experience in general. For example, viewing an ugly but famous artwork is part of aesthetic experience but may have no experience of beauty evoked (Pearce et al., 2016).
} 
algorithmic-representational or computational levels. Thus, one way to define the common neurobiological implementation of beauty is to test the existence of overlapping brain regions when experiencing the beauty from different sources (e.g., faces or visual art rated as beautiful). This overlap-based approach has been widely used to search the common neural basis of different cognitive processes. For instance, recent studies reported that the right inferior parietal lobule engaged in processing spatial, temporal, and social distance (Parkinson, Liu, \& Wheatley, 2014), the left intraparietal sulcus was associated with processing both perceptually salient and socially salient stimuli (Sui, Liu, Mevorach, \& Humphreys, 2015), and the dorsal anterior cingulate cortex and the left anterior insula were involved in processing both psychological and physical selves (Hu et al., 2016). In this sense, a common neural basis for different forms of beauty can be identified if there are common regions activated by experiencing different forms of beauty. The question remains: are there such common brain regions that convergently are activated with different forms of beauty? There are contradictory arguments to this question.

Some researchers claimed that a brain region specific to beauty exists, regardless of the sources of beauty and task type (Ishizu \& Zeki, 2011, 2013; Zeki, Romaya, Benincasa, \& Atiyah, 2014). For instance, Ishizu and Zeki (2011) reported that the medial orbitofrontal cortex (mOFC) is activated when experiencing both musical and visual beauty. The follow-up work from the same group showed that viewing mathematical formulas also activated the mOFC (Zeki et al., 2014). Based on these results, Ishizu and Zeki (2011) concluded that there is a single neural characteristic within the mOFC associated with the experience of beauty. Other researchers proposed that the experience of beauty activated a network of connected brain regions instead of a single brain region; the network includes synchronized activity over the occipital, parietal, and frontal regions (Cela-Conde et al., 2013; Chatterjee \& Vartanian, 2014; Vessel, Starr, \& Rubin, 2012). That is, aesthetic experiences are dynamic states arising from the interactions between sensory-motor, emotion-valuation, and meaningknowledges neural systems. ${ }^{2}$

Furthermore, some researchers argued that different forms of beauty might be associated with common brain region(s), but the region(s) might not be specific to beauty. For example, the ventromedial prefrontal cortex (vmPFC, which includes $\mathrm{mOFC}$ and adjacent brain regions) is not only activated when experiencing beauty but also when processing hedonic values (Nadal et al., 2008; Pegors, Kable, Chatterjee, \& Epstein, 2015; Skov, 2019; Skov \& Nadal, 2018). Similarly, they proposed that the experience of beauty could not be distinguished from general pleasure (Nadal \& Skov, 2018) and share the neural basis with other pleasure (Berridge \& Kringelbach,

\footnotetext{
${ }^{2}$ We appreciate this comment from an anonymous reviewer.
}

2015; Kringelbach \& Berridge, 2009). Based on the qualitative comparison of meta-analyses from neuroaesthetics and reward processing, Skov (2019) argued that there may be the same underlying neural mechanisms for experiencing aesthetic objects and assessing values, such as liking for food and drinks. Although disagreeing on whether the vmPFC is beauty-specific, these researchers agree that the vmPFC is a common brain region associated with the experience of beauty.

In contrast to the evidence suggesting that the $\mathrm{vmPFC/}$ mOFC is the center of beauty in the brain, others reported different neural basis associated with the experience of beauty. For example, Silveira, Fehse, Vedder, Elvers, and HennigFast (2015) found that paintings from the Museum of Modern Art elicited higher involvement of right precuneus, bilateral anterior cingulate cortex (ACC), and temporoparietal junction (TPJ), but not mOFC. Moreover, Brown, Gao, Tisdelle, Eickhoff, and Liotti (2011) conducted a metaanalysis focusing on an aesthetic appraisal. They examined the overlapping brain voxels associated with aesthetic appraisals from different modalities, including visual, audition, gustation, and olfaction. They found that a common neural basis might exist in the insula, a region typically associated with reward and emotion.

No conclusive findings in the field partially reflect that much evidence comes from theoretical analysis using studies with great variability in task and data analysis. Thus, the primary aim of the current study was to conduct a meta-analysis of neuroimaging studies of beauty to examine the cross-study convergence. The meta-analytical approach will overcome the common issues of low statistical power (Button et al., 2013) and high false-positive rates (Carp, 2012; Eklund, Nichols, \& Knutsson, 2016; Wager, Lindquist, \& Kaplan, 2007) in single neuroimaging studies by using the activation likelihood estimation (ALE) (Hu, Di, Li, Sui, \& Peng, 2015; Wager et al., 2007). This approach is a well-developed coordinate-based meta-analysis technique which accommodates the spatial uncertainty of activation data in neuroimaging studies and allows researchers to form statistically defensible conclusions (Eickhoff et al., 2016; Fox, Lancaster, Laird, \& Eickhoff, 2014; Laird et al., 2011). Note, we focused on the neuroimaging studies of the experience of visual beauty (Pearce et al., 2016). Specifically, we focused on the studies that compared the neural activities associated with the faces and visual arts (i.e., paintings, visual patterns, architectures, and dances) rated as beauty to those rated as nonbeauty. These two forms of beauty were selected because faces and visual arts represent two typical categories of beauty. Face beauty is the most representative natural beauty in social life, the preference of which is shaped by both evolution (Little, Jones, and DeBruine, 2011) and environment (Germine et al., 2015), whereas visual art is the most representative artificial beauty that reflects the subjective aesthetic preference of human beings (Skov \& Nadal, 2020). 
Another methodological reason for this is that these lines of research could provide enough amount of studies for a metaanalysis with reasonable statistical power (Müller et al., 2018). A comparison of the ALE results of fMRI studies between these two types of beauty may provide reliable and meaningful results, which could serve as a valuable starting point for exploring a common neural representation of beauty.

Given that beauty is an abstract concept and difficult to define (Bergeron \& Lopes, 2012; Conway \& Rehding, 2013), the present meta-analysis used operational criteria for study selection. That is, we looked into the literature and checked whether a neuroimaging study not only used faces or visual art as stimuli but also reported the activities evoked by stimuli rated as beautiful (vs. not beautiful) or preferred (vs. not preferred). Specifically, fMRI studies reported the contrast between stimuli rated as beautiful versus stimuli rated as not beautiful, or studies in which the authors argued that the results contained the neural activities related to the subjective feeling of beauty in different tasks, such as aesthetic judgement, asymmetry judgment, or passive viewing. We assumed that a meta-analysis that synthesized these existing studies independent of task type could capture the common neural basis for the subjective feeling of beauty.

The goals of the current study were to (1) identify common brain regions activated by both the experience of visual art and face beauty, and (2) assess the specific brain regions activated by either the beauty of faces or the beauty of visual art. To fulfill these goals, we first conducted a systematic literature search of the neuroimaging studies on the beauty of visual art and face; we selected articles that included the brain data of experiencing beauty. Based on the data extracted from 49 selected neuroimaging studies, we conducted ALE metaanalyses for the beauty of visual art and the beauty of faces separately. Then, we applied conjunction and contrast analyses to the meta-analytical results to identify the common and distinct neural basis of the beauty of visual art and faces. In addition to this primary meta-analysis, we conducted another two sets of meta-analysis to assess the effect of heterogeneity of studies - an important issue in meta-analysis, one with a restrict criterion that only focused on the studies using a specific task (i.e., an explicit aesthetic judgment task), the other with a liberal criterion that included the studies regardless of stimulus domain and task type.

\section{Methods}

\section{Literature search and study selection}

Articles included in the present meta-analyses were identified based on a systematic literature search using specific terms in PubMed and the Web of Science (up to Dec 12, 2018). "Face" or "facial" were paired with "attractiveness," "beauty" or "aesthetic" for aesthetic studies of faces; and "paintings," "visual art," "architecture," or "dance" were paired with "beauty" or "aesthetic" for aesthetic studies of visual art. All terms were each combined ("AND") with "functional magnetic resonance imaging or fMRI" or "positron emission tomography or PET" to identify relevant functional neuroimaging studies. For complete coverage, articles also were identified from recent metaanalyses and reviews (Boccia et al., 2016; Brown et al., 2011; Bzdok et al., 2011; Kirsch, Urgesi, \& Cross, 2016; MendeSiedlecki, Said, \& Todorov, 2013; Vartanian \& Skov, 2014). Additional studies were identified by searching through the reference lists of studies obtained via the initial search.

In our primary analysis, we selected studies based on the following inclusion and exclusion criteria:

(1) Only studies reporting whole-brain analyses were included, whereas studies based on partial coverage or employing only region-of-interest analyses were excluded. One study was included after the author provided the whole-brain analyses with the contrast of current metaanalyses (Lebreton, Jorge, Michel, Thirion, \& Pessiglione, 2009).

(2) Articles reported results as coordinates in a standard reference frame (Talairach and Tournoux or MNI). To address problems induced by different coordinates used across the studies, we converted those coordinates published in the Talairach space to the MNI space using the Lancaster transformation (Lancaster et al., 2007).

(3) Only studies with nonexpert young and middle-aged adults (18-50 years old) were included. Studies that included art experts were excluded if they did not report results for nonexperts separately (Kirk, Skov, Christensen \& Nygaard, 2009) due to the influence of expertise on aesthetic appreciation (Hekkert \& Wieringen, 1996).

(4) Studies investigated the beauty appreciation of visual art or faces. Given that we are interested in the experience of beauty, we only included studies that reported the effect of beauty, i.e., the contrast between stimuli that was rated as beautiful versus stimuli that was rated as not beautiful. We further derived three subcriteria for this standard: 4a) studies using visual art or art-like stimuli or faces as stimuli; 4b) studies reporting the effect of beauty or the subjective preference for visual art or faces separately and directly, therefore, studies using visual art or faces as stimuli that did not report the effect of beauty or preference were excluded; also studies that did not report the effect of faces or visual art separately were excluded; and 4c) studies reported the effect of beauty by contrast the stimuli rated as beautiful to a high-level baseline (i.e., stimuli that have similar physical properties, e.g., luminance, visual complexity, but not rated as beautiful or not preferred by the participants), instead of low-level 
baselines (e.g., fixation or blank screen), so that the contrast included were specific to effect of beauty, instead of a combined effect of beauty and visual properties.

Coordinates of the peak activations of brain regions, which serves as our principal measures, were extracted from each article by searching the contrast of interest from both the main text and supplementary materials. For each experiment, only one contrast's coordinate data were extracted. Beside the coordinates data, we also reported the number of valid participants, mean age or range of age, number of male participants, modality (fMRI or PET), stimuli, tasks, and the contrast from which the data were entered our meta-analyses (Table 1).

\section{Data analysis}

In addition to the primary analysis that used the abovementioned four criteria, we also conducted two supplementary analyses. The first meta-analysis tested whether increasing the homogeneity of the included studies would result in better convergence among the included studies. To do this, a metaanalysis only included the studies using a specific task (i.e., an explicit aesthetic judgment task) from the primary meta-analysis. In contrast, another meta-analysis examined whether increasing the number of included studies would result in a better convergence because of greater statistical power. However, the liberal criterion also might increase the heterogeneity of studies for meta-analysis instead. If this is true, we would expect weaker results in this meta-analysis with liberal criteria compared with the primary analysis (see Supplementary Material). In this liberal meta-analysis, we selected studies without applying the subcriteria $4 \mathrm{~b}$ and $4 \mathrm{c}$.

\section{Activation likelihood estimation}

The revised ALE algorithm, which was implemented in Matlab code, for the coordinate-based meta-analysis of neuroimaging results (Eickhoff et al., 2009; Laird, Eickhoff, et al., 2009; Laird, Lancaster, \& Fox, 2009; Turkeltaub, Eden, Jones, \& Zeffiro, 2002). This algorithm was designed to identify areas that exhibit a convergence of reported coordinates across experiments that is higher than expected under a random spatial association. The key idea behind ALE is to treat the reported foci not as single points but rather as centers for 3D Gaussian probability distributions that capture the spatial uncertainty associated with each focus. The Full-Width HalfMaximum (FWHM) of these Gaussian functions was determined based on empirical data on the between-subject variance by the number of examined subjects per study, accommodating the notion that larger sample sizes should provide more reliable approximations of the "true" activation effect and, therefore, should be modeled by "smaller" Gaussian distributions (Eickhoff et al., 2009). Specifically, the number of subjects in the studies in our meta-analysis ranged from 6-87, with a median of 18 , and the range of Full-Width Half-Maximum (FWHM) was from 8.5-10.94 mm (median: $9.5 \mathrm{~mm}$ ).

The probabilities of all foci reported in a given experiment were then combined for each voxel, resulting in a modeled activation (MA) map (Turkeltaub et al., 2012). Taking the union across these MA maps yielded voxel-wise ALE scores that described the convergence of the results across experiments at each location of the brain. To distinguish 'true' convergence among studies from random convergence (i.e., noise), we compared ALE scores to an empirical null distribution reflecting a random spatial association among experiments. A random-effects inference was invoked, focusing on the inference on the above-chance convergence among studies rather than the clustering of foci within a particular study. Computationally, deriving this null-hypothesis involved sampling a voxel at random from each of the MA maps and taking the union of these values in the same manner as performed for the (spatially contingent) voxels in the true analysis, a process that can be solved analytically (Eickhoff, Bzdok, Laird, Kurth, $\&$ Fox, 2012). The $p$ value of the "true" ALE was then given by the proportion of equal or higher values obtained under the null-distribution. The resulting nonparametric $p$ values were then thresholded at the $p<0.05$ (cluster-level corrected for multiple-comparison; cluster-forming threshold $p<0.001$ at voxel level) (Eickhoff et al., 2012). All significant clusters were reported, and the volume, weighted center and locations, and Z-scores at the peaks within the regions are given.

\section{Contrast and conjunction analysis of individual meta- analyses}

To explore the distinct and common neural basis for two forms of beauty, we further conducted contrast and conjunction analyses based on the ALE results. Differences between conditions were tested by first performing separate ALE analyses for each condition and computing the voxel-wise difference between the ensuing ALE maps. All experiments contributing to either analysis were then pooled and randomly divided into two groups of the same size as the two original sets of experiments reflecting the contrasted ALE analyses (Eickhoff et al., 2011; Rottschy et al., 2012). The ALE scores for these two randomly assembled groups were calculated, and the differences between the ALE scores were recorded for each voxel in the brain. Repeating this process 25,000 times then yielded a null-distribution of differences in ALE scores between the two conditions. The "true" difference in the ALE scores was then tested against this voxel-wise nulldistribution of label-exchangeability and thresholded at a probability of $p>95 \%$ for true differences. The conjunction analyses used the voxel-wise minimum of each single ALE results, i.e., finding the minimum $z$-value across the two 
(a)
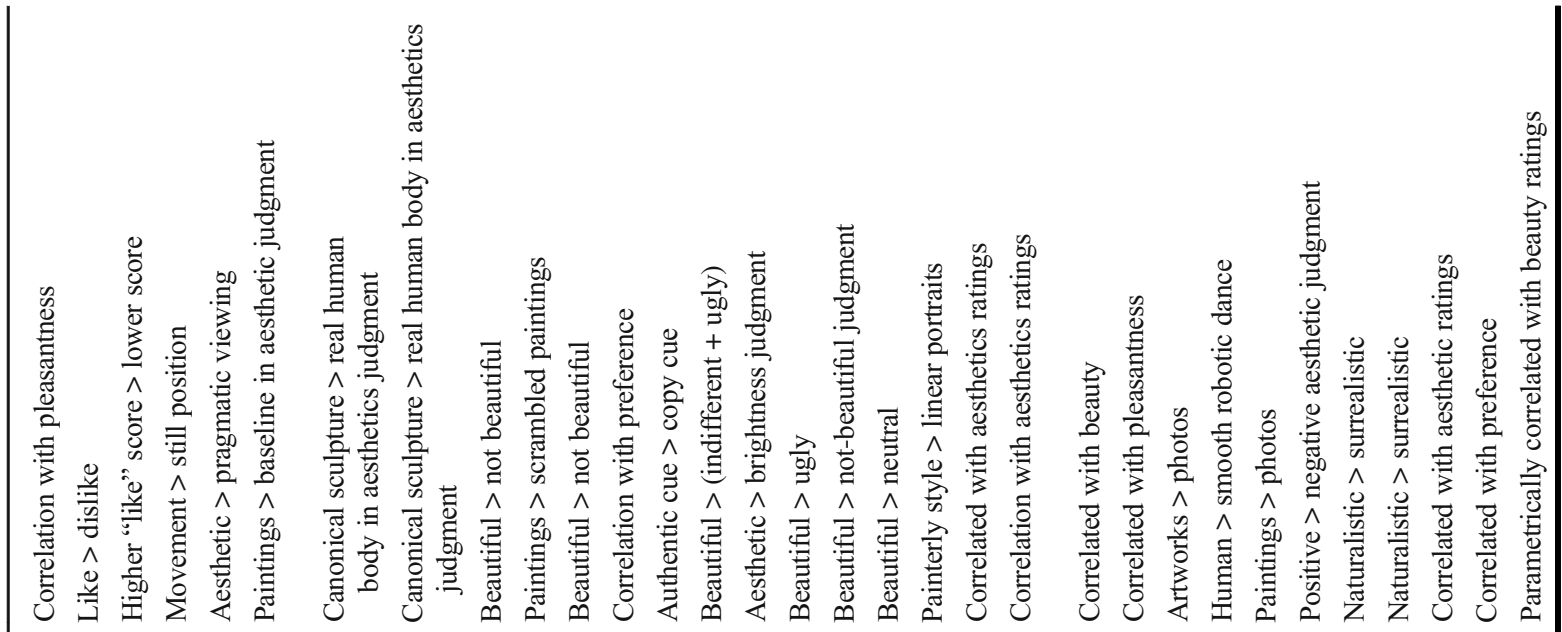

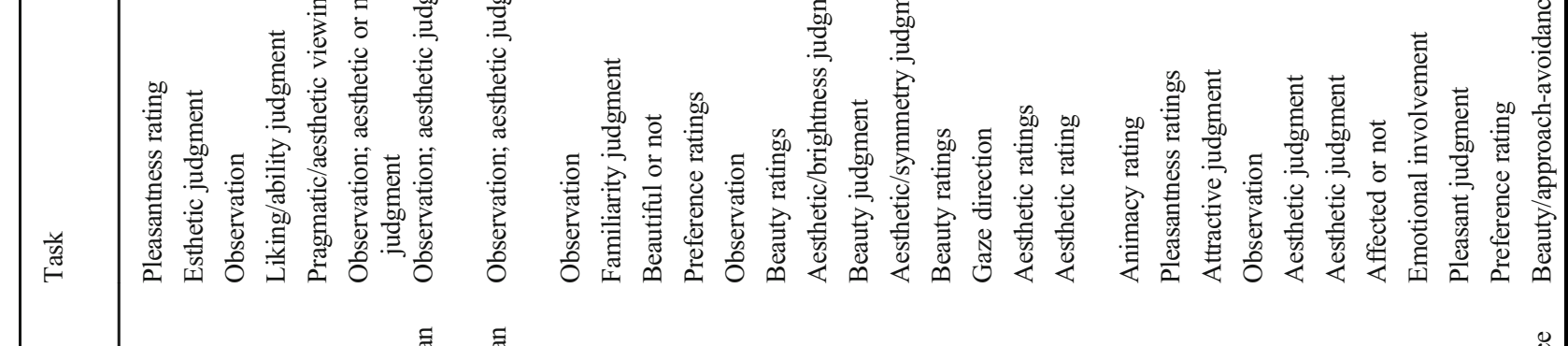

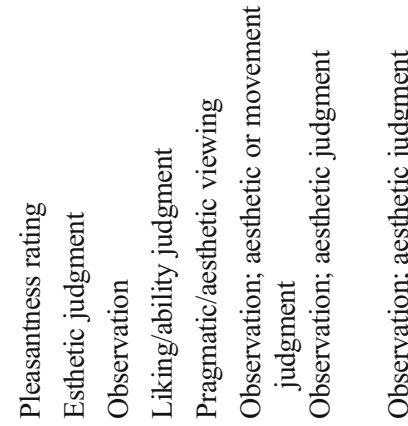

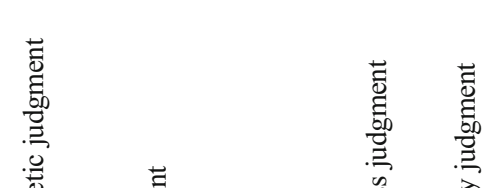

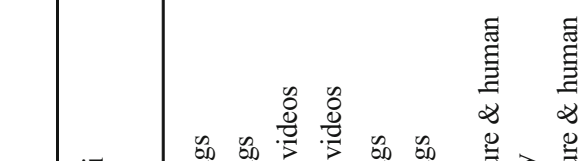

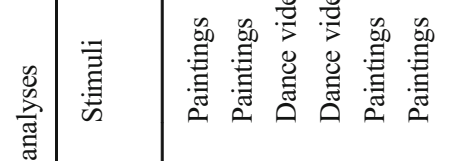

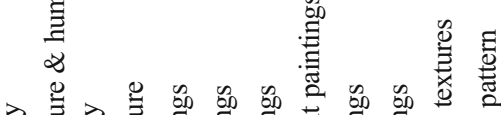

そ热

$\sum_{m} \sum_{m} \hat{\Sigma} \hat{\Sigma}$

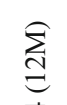

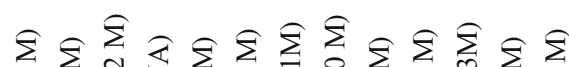

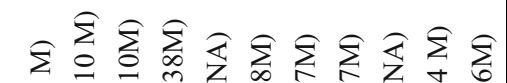
ปั

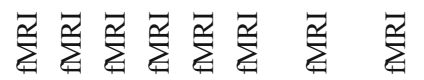

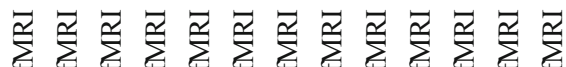

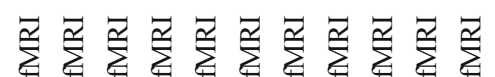

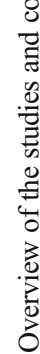

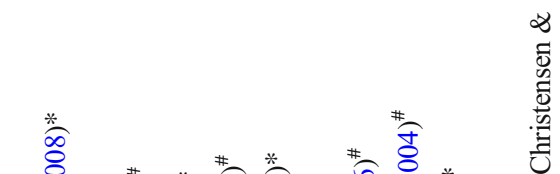

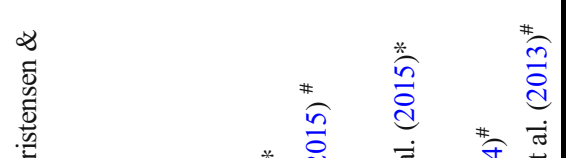

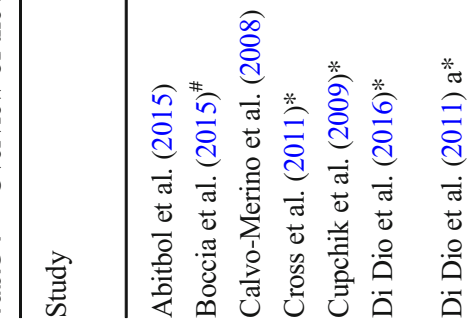

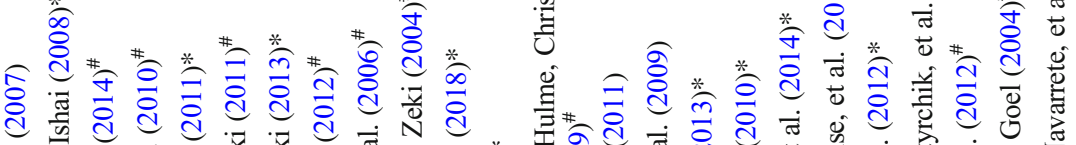

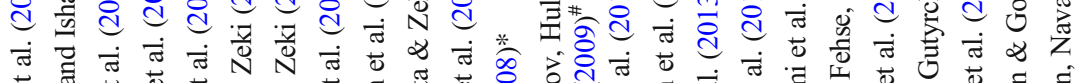

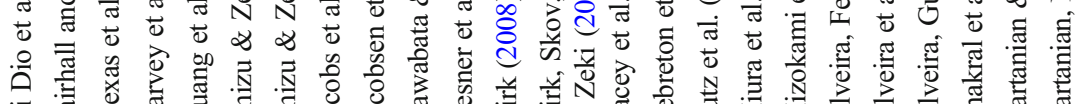




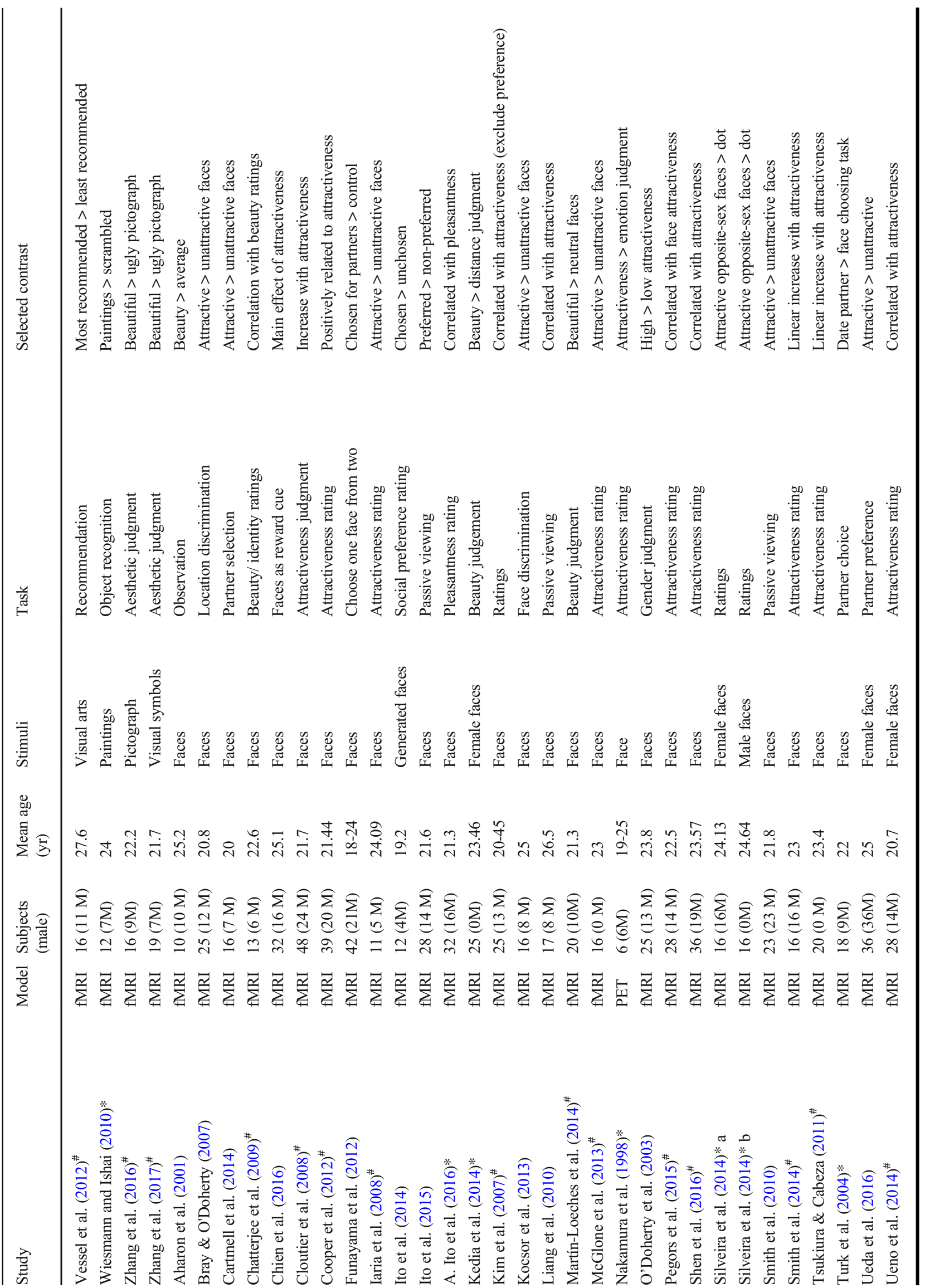


thresholded ALE results voxel-wisely (Nichols, Brett, Andersson, Wager, \& Poline, 2005).

\section{Data Visualization}

Given that there is no "gold standard" atlas for neuroimaging studies, we used probabilistic cytoarchitectonic maps (as implemented in SPM Anatomy Toolbox, the third version) (Amunts et al., 2013; Eickhoff, Heim, Zilles, \& Amunts, 2006; Eickhoff et al., 2007; Eickhoff et al., 2005) to assign our resulting coordinates to anatomical structures. For visualization purposes, BrainNet Viewer (Xia, Wang, \& He, 2013) was used.

\section{Results}

\section{Studies included in the meta-analyses}

Our primary analysis identified 49 articles: 20 articles for the beauty of visual arts, including 20 independent samples, 107 foci, and 295 subjects; 29 articles using attractive faces, including 29 independent sample, 183 foci, and 687 subjects. All of the code for search literature, endnote files for selecting articles, and metadata for the current study are available at https://osf.io/s9xds/. See Figure 1 for the process of article selection in detail and Table 1 for the information of selected articles.

\section{ALE Meta-analyses of the beauty of visual art and faces}

Our primary analyses revealed that the frontal pole was convergently activated by the beauty of visual art. This brain region also was labeled as the anterior medial prefrontal cortex (aMPFC) in the literature (Table 2; Figure 2A). The ALE results of the beauty of faces showed that two brain regions were more convergently activated: the first region located in the ventromedial prefrontal cortex (vmPFC) extending to the pgACC; the second region includes subcortical structures such as the ventral striatum and subcallosal cortex (Table 2; Figure 2B).

Critically, the conjunction analysis found no survival cluster (see Supplementary Results for the additional exploration of the results). The contrast analysis further revealed that a locus within the pgACC and a locus within the left ventral striatum were more frequently activated by beautiful faces than by beautiful art, while there the left frontal pole was more activated by visual art rated as beautiful than by faces rated as beautiful (Table 3; Figure 2C).

\section{Meta-analyses with conservative inclusion standards}

The first supplementary meta-analysis with more conservative inclusion standards (both explicit beauty judgment and beauty 


\section{a Article Selection for the beauty of visual art}

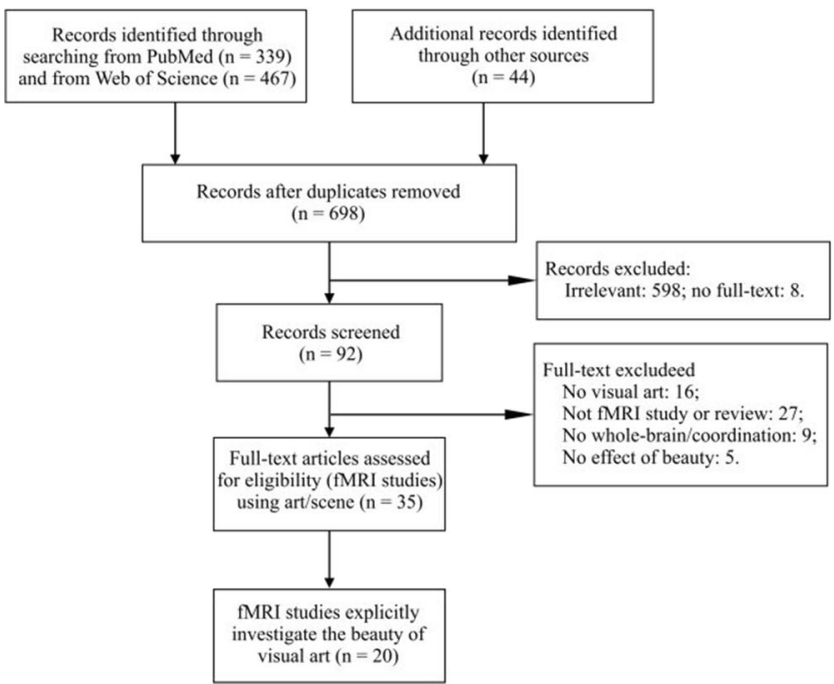

b Article Selection for the beauty of faces

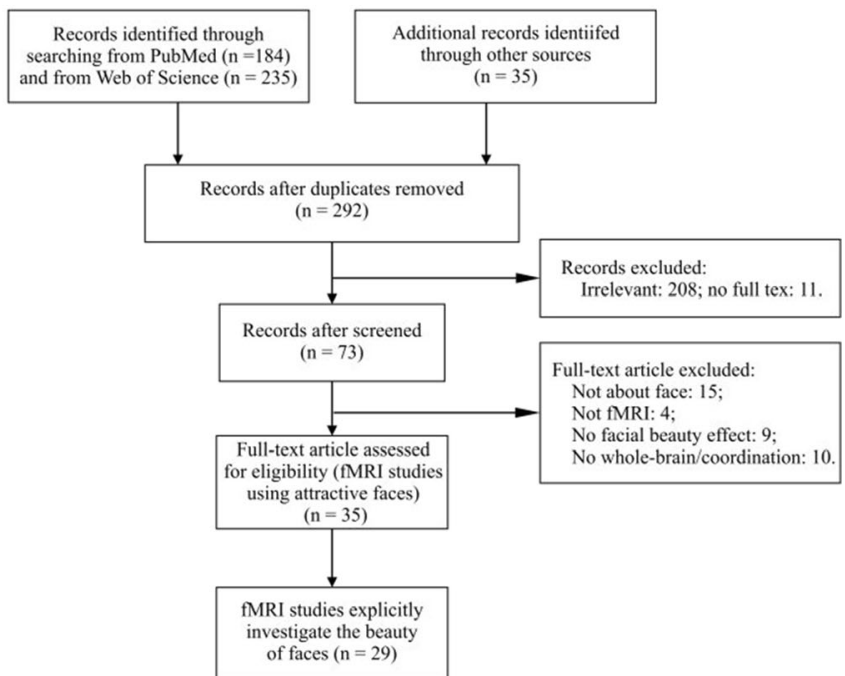

Figure 1. Literature search for the beauty of visual art (A) and the beauty of faces (B), adapted from Liberati et al. (2009).

vs. nonbeauty contrast) resulted 11 studies for visual art (54 foci, 192 subject) and 16 studies for faces (97 foci, $383 \mathrm{sub-}$ ject). The analysis of the beauty of visual art did find any survival clusters. The analysis of beautiful faces resulted in one brain regions as in primary analysis: the pgACC (Table 4). These results suggested that there was not convergent activation for the experience of beauty across studies that used explicit beauty judgment task. Interestingly, metaanalysis with liberal inclusion standards (Supplementary Analysis 1) also did not show survived clusters for the beauty of visual art, but found similar results as in primary analysis for the beauty of faces: both vmPFC (extending to the pgACC) and the ventral striatum (extending to subcallosal cortex) were convergently activated (see Table S2 in Supplementary Materials).

\section{Discussion}

The present study was designed to test the convergent neural basis of experiencing the beauty of visual art and faces. The results did not reveal any overlapped brain regions linked to the two forms of visual beauty, but each of which was associated with distinct brain regions. The $\mathrm{VMPFC} /$ frontal

Table 2 Results of the meta-analyses for visual art and faces rated as beautiful

\begin{tabular}{|c|c|c|c|c|c|c|c|c|c|}
\hline \multirow[t]{2}{*}{ Cluster } & \multirow{2}{*}{$\begin{array}{l}\text { Volume } \\
\text { (voxels) }\end{array}$} & \multicolumn{3}{|c|}{ Weighted center } & \multirow{2}{*}{$\begin{array}{l}\text { Maximum } \\
\text { Z-value }\end{array}$} & \multicolumn{3}{|c|}{ Center for maximum Z-value } & \multirow[t]{2}{*}{ Macroanatomical location } \\
\hline & & $\mathrm{x}$ & $\mathrm{y}$ & $\mathrm{z}$ & & $\mathrm{x}$ & $\mathrm{y}$ & $\mathrm{z}$ & \\
\hline \multicolumn{10}{|c|}{ Visual art rated as beautiful $>$ rated as not beautiful } \\
\hline \multirow[t]{3}{*}{1} & \multirow[t]{3}{*}{149} & \multirow[t]{3}{*}{-12} & \multirow[t]{3}{*}{62} & \multirow[t]{3}{*}{-2} & 4.33 & -12 & 62 & -2 & Frontal pole \\
\hline & & & & & 3.97 & -4 & 60 & -2 & Frontal pole/paracingulate gyrus \\
\hline & & & & & 3.97 & -6 & 60 & -2 & Frontal pole/paracingulate gyrus \\
\hline \multicolumn{10}{|c|}{ Faces rated as beautiful $>$ rated as not beautiful } \\
\hline \multirow[t]{4}{*}{1} & \multirow[t]{4}{*}{393} & \multirow[t]{4}{*}{0} & \multirow[t]{4}{*}{48} & \multirow[t]{4}{*}{-6} & 5.56 & 0 & 48 & -6 & Paracingulate gyrus/Frontal medial cortex \\
\hline & & & & & 4 & -2 & 36 & 2 & Anterior cingulate gyrus \\
\hline & & & & & 3.7 & 2 & 36 & 10 & Anterior cingulate gyrus \\
\hline & & & & & 3.2 & -4 & 36 & -16 & Frontal medial cortex/paracingulate gyrus \\
\hline \multirow[t]{3}{*}{2} & \multirow[t]{3}{*}{121} & \multirow[t]{3}{*}{-10} & \multirow[t]{3}{*}{16} & \multirow[t]{3}{*}{-6} & 4.69 & -10 & 16 & -6 & Left accumbens/Left caudate \\
\hline & & & & & 3.84 & -8 & 10 & -16 & Subcallosal cortex \\
\hline & & & & & 3.84 & -8 & 10 & -14 & Subcallosal cortex/left accumbens \\
\hline
\end{tabular}

All peaks were assigned to the most probable brain area using the SPM Anatomy Toolbox v3. 
a ALE results of visual art

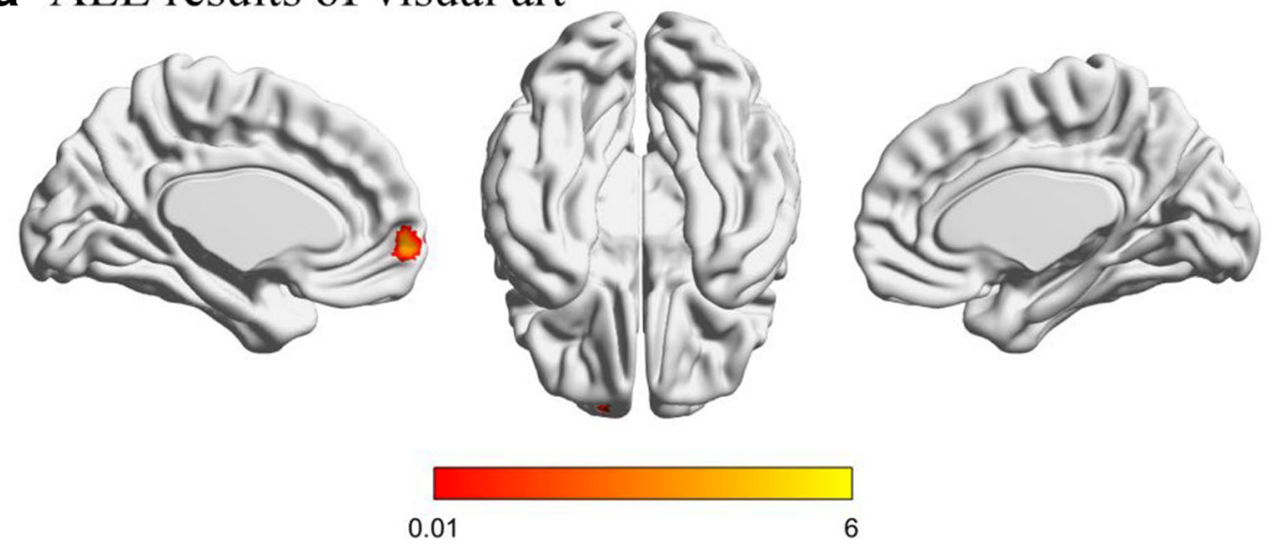

b ALE results of beatiful faces
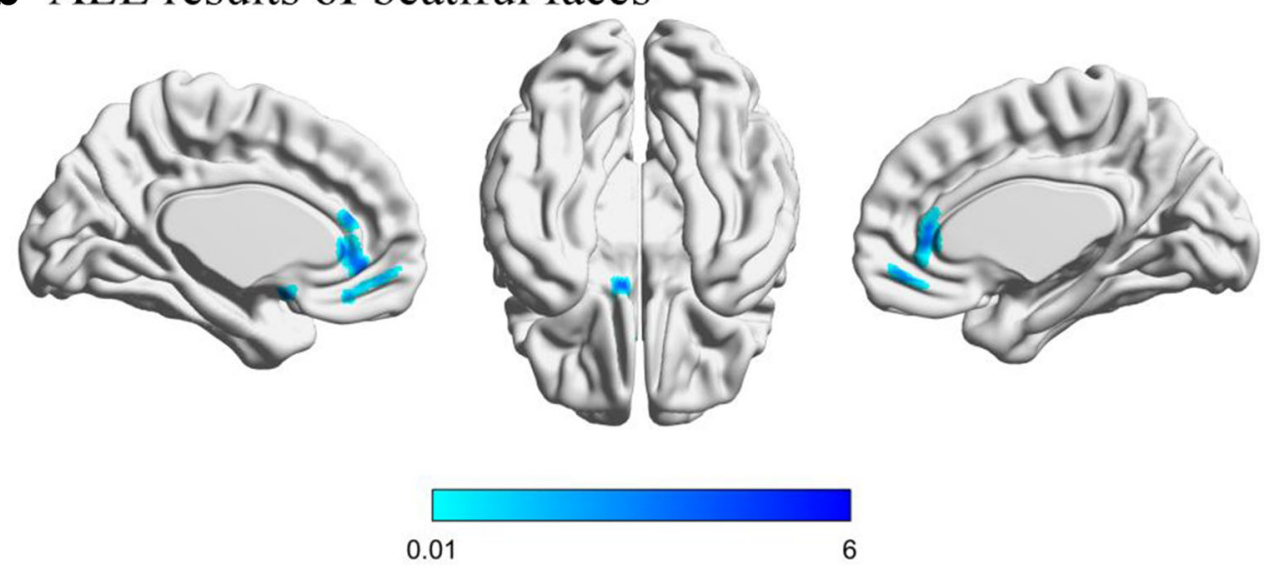

\section{c Contrast of the ALE results}
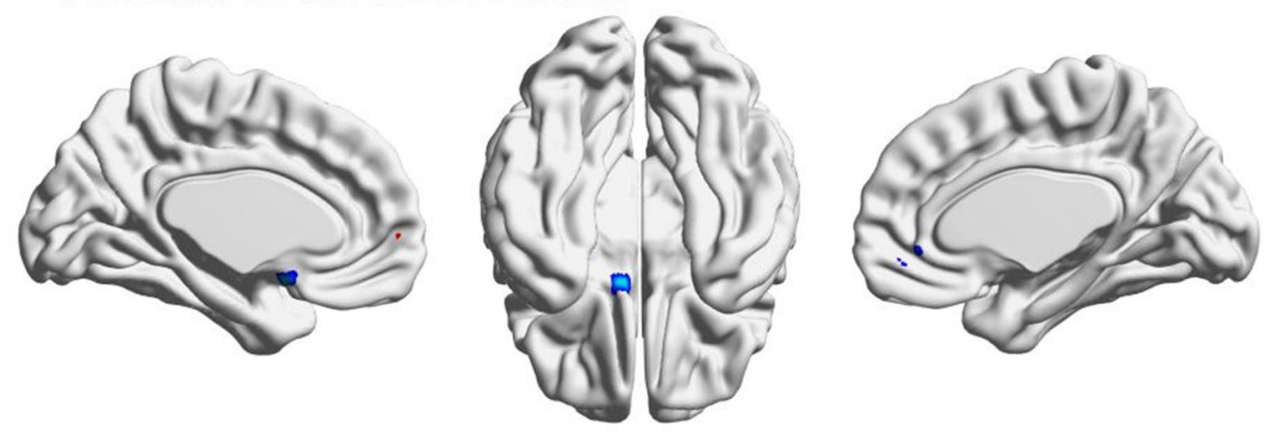

$-3$

Figure 2. Results of the ALE meta-analysis and the contrast analysis. (A) Brain regions convergently activated more for visual art rated as beautiful than for visual art rated as not beautiful. (B) Brain regions convergently activated more for faces rated as beautiful than for faces rated as not beautiful. (C) The results of the contrast analysis between the ALE results

pole was activated when experiencing visual art compared with face beauty rated, whereas the left ventral striatum and $\mathrm{vmPFC} / \mathrm{pgACC}$ were associated with the experience of face beauty contrasting to visual art.

\section{Is there a common neural basis for visual beauty?}

Previous fMRI studies on beauty suggested the vmPFC/ mOFC was involved in processing different forms of beauty 
Table 3 Contrast and conjunction analyses of the meta-analysis results

\begin{tabular}{|c|c|c|c|c|c|c|c|c|c|}
\hline \multirow[t]{2}{*}{ Cluster } & \multirow{2}{*}{$\begin{array}{l}\text { Volume } \\
\text { (voxels) }\end{array}$} & \multicolumn{3}{|c|}{ Weighted center } & \multirow{2}{*}{$\begin{array}{l}\text { Maximum } \\
\text { Z-value }\end{array}$} & \multicolumn{3}{|c|}{ Center for maximum Z-value } & \multirow[t]{2}{*}{ Macroanatomical location } \\
\hline & & $\mathrm{x}$ & $\mathrm{y}$ & $\mathrm{z}$ & & $\mathrm{x}$ & $\mathrm{y}$ & $\mathrm{z}$ & \\
\hline \multicolumn{10}{|c|}{ Beauty of visual art $>$ beauty of faces } \\
\hline 1 & 30 & -12 & 58 & 2 & 1.98 & -12 & 58 & 2 & Frontal pole/paracingulate gyrus \\
\hline \multicolumn{10}{|c|}{ Beauty of faces $>$ beauty of visual art } \\
\hline 1 & 48 & 4 & 46 & -2 & 2.23 & 4 & 46 & -2 & Paracingulate gyrus/anterior cingulate gyrus \\
\hline 2 & 45 & -6 & 6 & -16 & 2.78 & 6 & 6 & -16 & L. accumbens/subcallosal cortex \\
\hline
\end{tabular}

Beauty of visual art $\cap$ beauty of faces

No cluster survived

All peaks were assigned to the most probable brain area using the SPM Anatomy Toolbox v3.

(Ishizu \& Zeki, 2011, 2013; Nadal et al., 2008; Pegors et al., 2015; Skov, 2019; Skov \& Nadal, 2018; Zeki et al., 2014). It also has been reported that the vmPFC serves as a hub for subjective values (Etkin, Egner, Peraza, Kandel, \& Hirsch, 2006; Levy \& Glimcher, 2012; Roy, Shohamy, \& Wager, 2012), positive signals (Bartra, McGuire, \& Kable, 2013; Kalisch et al., 2006), and self-referential processes (Hu et al., 2016; Northoff et al., 2006). By synthesizing the available neuroimaging studies that examined the beauty of faces and visual art, the present meta-analysis did not find a convergent result between the neural activations elicited by these two forms of beauty. Moreover, this null result was robust even by increasing the homogeneity of the included studies. Given the strong statistical power of meta-analysis and its capacity to address the cross-study variance, the present results suggest that the common neural basis of beauty may not exist (also see Supplementary Materials).

One might argue that our primary meta-analysis was based on loose-defined operationalized criteria, which led to the high heterogeneity of the included studies (e.g., studies using different tasks). The heterogeneity resulted in the null result of the conjunction. However, the argument was not supported by the meta-analysis using the conservative inclusive criteria, which failed to show convergent results. Although the additional meta-analysis, which had a small number of studies, might suffer from low statistical power, in contrast to the convergent results in the primary analysis, it suggests that heterogeneity was less important than the number of studies in the current analysis. These results indicated that the primary analysis, with a relatively large number of studies, at least detected some shared mental processes associated with the experience of beauty. Otherwise, if the studies with different tasks evoked different mental processes (i.e., increased heterogeneity), the primary meta-analysis should have found less convergent results than the meta-analysis with conservative criteria.

Understanding a common mechanism of experience beauty is of great interest not only in empirical aesthetics but also in aesthetics in general because of the long-last debate about the center of beauty. Previous theories in neuroaesthetics suggest a common neural basis representing beauty in the brain (Ishizu \& Zeki, 2011, 2013; Nadal et al., 2008; Pegors et al., 2015; Skov, 2019; Skov \& Nadal, 2018; Zeki et al., 2014). However, this view was not supported by the present meta-analyses.

The discrepancy between the strong theoretical prediction of a common neural basis for beauty and lack of empirical evidence calls for more rigorous studies. Recently, the field of cognitive neuroscience has been challenged for its reproducibility (Botvinik-Nezer et al., 2020; Hu, Jiang, Jeffrey, \& Zuo, 2018; Poldrack et al., 2017). Small sample size (which results in low statistical power) (Button et al., 2013), flexibility in data analysis (Botvinik-Nezer et al., 2020; Carp, 2012), and errors in implementing software (Eklund et al., 2016), accompanied by publication bias (Jennings \& Horn, 2012), all threatened the reliability and reproducibility of the field ( $\mathrm{Hu}$ et al., 2018; Poldrack et al., 2017). Direct replication, albeit very few, found that pessimistic results (Boekel et al., 2015). To better test the

Table 4 Results of the meta-analysis with conservative inclusive standards

\begin{tabular}{|c|c|c|c|c|c|c|c|c|c|}
\hline \multirow[t]{2}{*}{ Cluster } & \multirow{2}{*}{$\begin{array}{l}\text { Volume } \\
\text { (voxels) }\end{array}$} & \multicolumn{3}{|c|}{ Weighted center } & \multirow{2}{*}{$\begin{array}{l}\text { Maximum } \\
\text { Z-value }\end{array}$} & \multicolumn{3}{|c|}{ Center for maximum $\mathrm{Z}$-value } & \multirow[t]{2}{*}{ Macroanatomical location } \\
\hline & & $\mathrm{x}$ & $\mathrm{y}$ & $\mathrm{z}$ & & $\mathrm{x}$ & $\mathrm{y}$ & $\mathrm{z}$ & \\
\hline
\end{tabular}

Visual art rated as beautiful $>$ as not beautiful (No cluster survived)

Faces rated as beautiful $>$ as not beautiful

$\begin{array}{llllllllll}1 & 93 & -2 & 36 & 2 & 4.26 & -2 & 36 & 2 & \text { Anterior cingulate gyrus }\end{array}$


common neural basis of beauty, researchers need to adopt new practices that have been recommended recently, including the standard reporting, preregistration, and large sample size (Munafò et al., 2017). Also, as science is accumulative, further studies can be integrated into the current meta-analysis to update the results. To facilitate this process, we have opened the metadata of this meta-analysis (see Method section). Future works can easily be integrated to update the knowledge about the common neural basis of beauty.

\section{Unique neural basis underlying the beauty of faces and visual art}

The ALE results of face beauty demonstrated that experiencing face beauty induced greater activation in the $\mathrm{vmPFC/}$ pgACC and the left ventral striatum than when faces rated as not beautiful. In contrast, the ALE results of the beauty of visual art showed convergent activations in the left frontal pole/aMPFC related to visual art rated as not beautiful. The result was consistent with previous studies demonstrating that the vmPFC-subcortical rewarding system is engaged in processing the beauty of faces (Chatterjee \& Vartanian, 2014; Hahn \& Perrett, 2014). On the other hand, the vmPFC/ pgACC and the ventral striatum play different roles in cognition. For example, the vmPFC/pgACC is activated with a wide range of brain structures when involved in multiple higher-level functions (de la Vega, Chang, Banich, Wager, \& Yarkoni, 2016; Roy et al., 2012). It has consistently been reported that the ventral striatum is engaged in reward processing (Haber \& Knutson, 2010; Liu, Hairston, Schrier, \& Fan, 2011), especially primary reward (Sescousse, Caldú, Segura, \& Dreher, 2013). Therefore, it is possible the facial beauty is appreciated through a ventral pathway: the ventral striatum primarily responds to the rewarding value of faces, the reward signal, along with other information, and then integrated into the vmPFC to generate positive affections.

In contrast, the frontal pole/aMPFC convergently activated in appreciating the beauty of visual art is more engaged in high-level, top-down processing. Previous studies have shown that it involves in episodic memory, decision-making, and social cognition (de la Vega et al., 2016), such as positive evaluation (Bartra et al., 2013) and secondary reward (Sescousse et al., 2013). We speculated that the aMPFC, when appreciating visual art, links more abstract beauty to reward, like that of secondary reward.

\section{Role of the sensory cortex and hemispheric differences in processing beauty}

We did not find activations in the sensory regions in metaanalyses of either the beauty of faces or the beauty of visual art. For the facial beauty, no significant activations in either the fusiform face areas or other sensory cortical areas were observed when rating faces as beautiful contrasting to rating faces as not beautiful. Likewise, there was no activation of the sensory-motor network observed when experiencing the beauty of visual art. These results seem to contradict previous theories about facial beauty (Chatterjee et al., 2009; Iaria et al., 2008) and art appreciating (Boccia et al., 2016; Chatterjee \& Vartanian, 2014; Leder \& Nadal, 2014).

One possibility of these results is that current metaanalyses exclusively included the contrasts between beautiful versus non-beautiful stimuli with similar perceptual features (high-level baselines, see Method section), therefore, eliminating the effect of the physical feature processing on the experience of visual beauty. If this is the case, the present results indicated that the beauty of faces and visual arts showed different neural representations at high-level processing.

Notably, our results do not suggest that physical features are less important in beauty appreciating. The sensory network is necessary for processing the beauty of faces and visual art (Chatterjee \& Vartanian, 2014). The shared standard for faces rated as beautiful (Hönekopp, 2006; Leder, Goller, Rigotti, \& Forster, 2016) suggests that physical features are crucial for experiencing visual beauty. Hence, future studies are needed to examine the contribution of sensory processing to beauty appreciation.

Regarding the hemisphere differences, it seems that peak locations in experiencing both face and art beauty appear in the left hemisphere, contradicting the view that the right brain is dominant for imagination, creativity, and emotions (Bromberger et al., 2011). However, our meta-analytic results did not reveal hemispheric asymmetry for experiencing beauty: most clusters were near the midline of the brain. The present results, together with the previous meta-analysis on appreciating visual art (Boccia et al., 2016), suggest that the visual beauty is processed by both hemispheres.

\section{Further considerations}

Based on the available research in the literature, the current metaanalysis attempted to examine whether there is a common beauty of faces and visual art in the brain and whether albeit each category of beauty had its convergent brain regions. One limitation of the current meta-analysis is that the analyses were based on the reported peak activations, which may have two disadvantages. First, a large part of the spatial information from the original study was discarded. However, this limitation can be alleviated by the fact that the results derived from image-based meta-analysis are in good agreement with coordinate-based meta-analysis approaches (Salimi-Khorshidi, Smith, Keltner, Wager, \& Nichols, 2009). Second, studies that did not report any activations for the contrast of interest were not included in the current analyses. Indeed, some studies used the beauty appreciation task but did not report the results of beautiful-non-beautiful contrast (Kampe, Frith, Dolan, \& Frith, 2001); therefore, they could not 
be included in our meta-analysis. However, this selection bias, if any, together with potential publication bias in neuroimaging studies (Jennings \& Horn, 2012), may result in inflated false positive. This inflated false-positive rate is not a concern for the current meta-analysis, because no positive results for the conjunction analysis were observed in the present study. A related issue is that coordinate-based, meta-analysis approaches of neuroimaging studies, such as ALE, use the averaged likelihood in common volumetric space (Wager et al., 2007); it might lead to false positives of convergent activation in adjacent regions across studies. However, this is not a concern in the current metaanalysis given our negative results.

The meta-analyses inherently include many seems trivial but important choices that bring extra flexibility in research practices. For example, the standard for inclusion may not be clear for a few papers, and results from more than one contrast are qualified with the inclusion standard. In these cases, the final choice might be arbitrary. Studies have shown that flexibility in research practice can inflate the false-positive rate (Botvinik-Nezer et al., 2020; Carp, 2012; Simmons, Nelson, \& Simonsohn, 2011). It also might be true for meta-analysis. To alleviate this limitation (Schönbrodt, Maier, Heene, \& Zehetleitner, 2015), we adopted an open and transparent practice and uploaded the article selection process (as recorded in Endnote ${ }^{\circledR}$ X8, Clarivate Analytics, Philadelphia, PA) and meta-data (see https://osf.io/s9xds/).

\section{Conclusions}

Our meta-analytic results revealed distinct neural specificities for visual art and face beauty but lacked evidence for the common neural basis of visual beauty. This null result suggests that the available data did not support the notion of the existence of a common brain for processing different forms of beauty. To support such a common neural basis for beauty, more rigorous studies are needed.

Acknowledgments This work was supported by the Economic and Social Research Council (UK, ES/K013424/1) and by the National Natural Science Foundation of China (Project 31371017, and 31471001). SBE acknowledges funding by the the National Institute of Mental Health (R01-MH074457) and the European Union's Horizon 2020 Research and Innovation Programme under Grant Agreement No. 945539 (HBP SGA3). We thank Dr. Steven Brown for helpful comments on the previous versions of this manuscript.

Author Contributions C-P. H. and K.P. designed the study. C-P.H. and S.E. performed the statistical analyses. C-P. H., Y.H., and J.S analyzed the findings and wrote the manuscript. All authors reviewed the manuscript.

\section{Compliance with ethical standards}

Competing financial interests The authors declare no competing financial interests.

\section{References}

Abitbol, R., Lebreton, M., Hollard, G., Richmond, B. J., Bouret, S., \& Pessiglione, M. (2015). Neural mechanisms underlying contextual dependency of subjective values: converging evidence from monkeys and humans. $J$ Neurosci, 35(5), 2308-2320. https://doi.org/10. 1523/jneurosci.1878-14.2015

Aharon, I., Etcoff, N., Ariely, D., Chabris, C. F., O'Connor, E., \& Breiter, H. C. (2001). Beautiful Faces Have Variable Reward Value: fMRI and Behavioral Evidence. Neuron, 32(3), 537-551. https://doi.org/ 10.1016/S0896-6273(01)00491-3

Amunts, K., Lepage, C., Borgeat, L., Mohlberg, H., Dickscheid, T., Rousseau, M.-É., ... Evans, A. C. (2013). BigBrain: An Ultrahigh-Resolution 3D Human Brain Model. Science, 340(6139), 1472-1475. https://doi.org/10.1126/science.1235381

Bartra, O., McGuire, J. T., \& Kable, J. W. (2013). The valuation system: A coordinate-based meta-analysis of BOLD fMRI experiments examining neural correlates of subjective value. NeuroImage, 76(0), 412-427. https://doi.org/10.1016/j.neuroimage.2013.02.063

Bergeron, V., \& Lopes, D. M. (2012). Aesthetic theory and aesthetic science. In A. P. Shimamura \& S. E. Palmer (Eds.), Aesthetic science: Connecting minds, brains, and experience (pp. 61-79). New York, US: Oxford University Press.

Berridge, Kent C., \& Kringelbach, Morten L. (2015). Pleasure Systems in the Brain. Neuron, 86(3), 646-664. https://doi.org/10.1016/j.neuron. 2015.02.018

Boccia, M., Barbetti, S., Piccardi, L., Guariglia, C., Ferlazzo, F., Giannini, A. M., \& Zaidel, D. W. (2016). Where does brain neural activation in aesthetic responses to visual art occur? Meta-analytic evidence from neuroimaging studies. Neurosci Biobehav Rev, 60, 65-71. https://doi.org/10.1016/j.neubiorev.2015.09.009

Boccia, M., Nemmi, F., Tizzani, E., Guariglia, C., Ferlazzo, F., Galati, G., \& Giannini, A. M. (2015). Do you like Arcimboldo's? Esthetic appreciation modulates brain activity in solving perceptual ambiguity. Behavioural Brain Research, 278, 147-154. https://doi.org/10.1016/ j.bbr.2014.09.041

Boekel, W., Wagenmakers, E.-J., Belay, L., Verhagen, J., Brown, S., \& Forstmann, B. U. (2015). A purely confirmatory replication study of structural brain-behavior correlations. Cortex, 66, 115-133. https:// doi.org/10.1016/j.cortex.2014.11.019

Botvinik-Nezer, R., Holzmeister, F., Camerer, C. F., Dreber, A., Huber, J., Johannesson, M., ... Schonberg, T. (2020). Variability in the analysis of a single neuroimaging dataset by many teams. Nature. https://doi.org/10.1101/843193

Bray, S., \& O'Doherty, J. (2007). Neural Coding of Reward-Prediction Error Signals During Classical Conditioning With Attractive Faces. J Neurophysiol, 97(4), 3036-3045. https://doi.org/10.1152/jn. 01211.2006

Bromberger, B., Sternschein, R., Widick, P., Smith, W., \& Chatterjee, A. (2011). The Right Hemisphere in Esthetic Perception. Front Hum Neurosci, 5(109). https://doi.org/10.3389/fnhum.2011.00109

Brown, S., Gao, X., Tisdelle, L., Eickhoff, S. B., \& Liotti, M. (2011). Naturalizing aesthetics: Brain areas for aesthetic appraisal across sensory modalities. NeuroImage, 58(1), 250-258. https://doi.org/ 10.1016/j.neuroimage.2011.06.012

Button, K. S., Ioannidis, J. P. A., Mokrysz, C., Nosek, B. A., Flint, J., Robinson, E. S. J., \& Munafo, M. R. (2013). Power failure: why small sample size undermines the reliability of neuroscience. Nat Rev Neurosci, 14(5), 365-376. https://doi.org/10.1038/nrn3475

Bzdok, D., Langner, R., Caspers, S., Kurth, F., Habel, U., Zilles, K., ... Eickhoff, S. B. (2011). ALE meta-analysis on facial judgments of trustworthiness and attractiveness. Brain Struct Func, 215(3), 209223. https://doi.org/10.1007/s00429-010-0287-4 
Calvo-Merino, B., Jola, C., Glaser, D. E., \& Haggard, P. (2008). Towards a sensorimotor aesthetics of performing art. Consciousness and Cognition, 17(3), 911-922. https://doi.org/10.1016/j.concog.2007.11.003

Carp, J. (2012). The secret lives of experiments: Methods reporting in the fMRI literature. NeuroImage, 63(1), 289-300. https://doi.org/10. 1016/j.neuroimage.2012.07.004

Cartmell, S. C. D., Chun, M. M., \& Vickery, T. J. (2014). Neural antecedents of social decision-making in a partner choice task. Soc Cogn Affect Neurosci, 9(11), 1722-1729. https://doi.org/10.1093/scan/nst168

Cela-Conde, C. J., García-Prieto, J., Ramasco, J. J., Mirasso, C. R., Bajo, R., Munar, E., .. Maestú, F. (2013). Dynamics of brain networks in the aesthetic appreciation. Proceedings of the National Academy of Sciences of the United States of America, 110 (Supplement 2), 10454-10461. https://doi.org/10.1073/pnas.1302855110

Chatterjee, A., Thomas, A., Smith, S. E., \& Aguirre, G. K. (2009). The neural response to facial attractiveness. Neuropsychology, 23(2), 135-143. https://doi.org/10.1037/a0014430

Chatterjee, A., \& Vartanian, O. (2014). Neuroaesthetics. Trends Cogn Sci, 18(7), 370-375. https://doi.org/10.1016/j.tics.2014.03.003

Chien, S., Wiehler, A., Spezio, M., \& Glaescher, J. (2016). Congruence of Inherent and Acquired Values Facilitates Reward-Based Decision-Making. Journal of Neuroscience, 36(18), 5003-5012. https://doi.org/10.1523/jneurosci.3084-15.2016

Cloutier, J., Heatherton, T. F., Whalen, P. J., \& Kelley, W. M. (2008). Are Attractive People Rewarding? Sex Differences in the Neural Substrates of Facial Attractiveness. J Cogn Neurosci, 20(6), 941951. https://doi.org/10.1162/jocn.2008.20062

Conway, B. R., \& Rehding, A. (2013). Neuroaesthetics and the Trouble with Beauty. PLoS Biol, 11(3), e1001504. https://doi.org/10.1371/ journal.pbio. 1001504

Cooper, J. C., Dunne, S., Furey, T., \& O'Doherty, J. P. (2012). Dorsomedial Prefrontal Cortex Mediates Rapid Evaluations Predicting the Outcome of Romantic Interactions. J Neurosci, 32(45), 15647-15656. https://doi. org/10.1523/jneurosci.2558-12.2012

Cross, E. S., Kirsch, L., Ticini, L. F., \& Schuetz-Bosbach, S. (2011). The impact of aesthetic evaluation and physical ability on dance perception. Frontiers in Human Neuroscience, 5. https://doi.org/10.3389/ fnhum.2011.00102

Cupchik, G. C., Vartanian, O., Crawley, A., \& Mikulis, D. J. (2009). Viewing artworks: Contributions of cognitive control and perceptual facilitation to aesthetic experience. Brain Cognition, 70(1), 84-91. https://doi.org/10.1016/j.bandc.2009.01.003

de la Vega, A., Chang, L. J., Banich, M. T., Wager, T. D., \& Yarkoni, T. (2016). Large-Scale Meta-Analysis of Human Medial Frontal Cortex Reveals Tripartite Functional Organization. J Neurosci, 36(24), 6553-6562. https://doi.org/10.1523/jneurosci.4402-15.2016

Di Dio, C., Ardizzi, M., Massaro, D., Di Cesare, G., Gilli, G., Marchetti, A., \& Gallese, V. (2016). Human, Nature, Dynamism: The Effects of Content and Movement Perception on Brain Activations during the Aesthetic Judgment of Representational. Frontiers in Human Neuroscience, 9. https://doi.org/10.3389/fnhum.2015.00705

Di Dio, C., Canessa, N., Cappa, S. F., \& Rizzolatti, G. (2011). Specificity of aesthetic experience for artworks: an fMRI study. Frontiers in Human Neuroscience, 5. https://doi.org/10.3389/fnhum.2011.00139

Di Dio, C., Macaluso, E., \& Rizzolatti, G. (2007). The Golden Beauty: Brain Response to Classical and Renaissance Sculptures. Plos One, 2(11), e1201. https://doi.org/10.1371/journal.pone.0001201

Eickhoff, S. B., Bzdok, D., Laird, A. R., Kurth, F., \& Fox, P. T. (2012). Activation likelihood estimation meta-analysis revisited. NeuroImage, 59(3), 2349-2361. https://doi.org/10.1016/j. neuroimage.2011.09.017

Eickhoff, S. B., Bzdok, D., Laird, A. R., Roski, C., Caspers, S., Zilles, K., \& Fox, P. T. (2011). Co-activation patterns distinguish cortical modules, their connectivity and functional differentiation. NeuroImage, 57(3), 938-949. https://doi.org/10.1016/j.neuroimage.2011.05.021
Eickhoff, S. B., Heim, S., Zilles, K., \& Amunts, K. (2006). Testing anatomically specified hypotheses in functional imaging using cytoarchitectonic maps. NeuroImage, 32(2), 570-582. https://doi. org/10.1016/j.neuroimage.2006.04.204

Eickhoff, S. B., Laird, A. R., Grefkes, C., Wang, L. E., Zilles, K., \& Fox, P. T. (2009). Coordinate-based activation likelihood estimation meta-analysis of neuroimaging data: A random-effects approach based on empirical estimates of spatial uncertainty. Hum Brain Mapp, 30(9), 2907-2926. https://doi.org/10.1002/hbm.20718

Eickhoff, S. B., Nichols, T. E., Laird, A. R., Hoffstaedter, F., Amunts, K., Fox, P. T., ... Eickhoff, C. R. (2016). Behavior, Sensitivity, and power of activation likelihood estimation characterized by massive empirical simulation. NeuroImage, 137, 70-85. https://doi.org/10. 1016/j.neuroimage.2016.04.072

Eickhoff, S. B., Paus, T., Caspers, S., Grosbras, M.-H., Evans, A. C., Zilles, K., \& Amunts, K. (2007). Assignment of functional activations to probabilistic cytoarchitectonic areas revisited. NeuroImage, 36(3), 511-521. https://doi.org/10.1016/j.neuroimage.2007.03.060

Eickhoff, S. B., Stephan, K. E., Mohlberg, H., Grefkes, C., Fink, G. R., Amunts, K., \& Zilles, K. (2005). A new SPM toolbox for combining probabilistic cytoarchitectonic maps and functional imaging data. NeuroImage, 25(4), 1325-1335. https://doi.org/10.1016/j. neuroimage.2004.12.034

Eklund, A., Nichols, T. E., \& Knutsson, H. (2016). Cluster failure: Why fMRI inferences for spatial extent have inflated false-positive rates. Proc Natl Acad Sci USA, 113(28), 7900-7905. https://doi.org/10. 1073/pnas.1602413113

Etkin, A., Egner, T., Peraza, D. M., Kandel, E. R., \& Hirsch, J. (2006). Resolving Emotional Conflict: A Role for the Rostral Anterior Cingulate Cortex in Modulating Activity in the Amygdala. Neuron, 51(6), 871-882. https://doi.org/10.1016/j.neuron.2006.07.029

Fairhall, S. L., \& Ishai, A. (2008). Neural correlates of object indeterminacy in art compositions. Consciousness and Cognition, 17(3), 923932. https://doi.org/10.1016/j.concog.2007.07.005

Flexas, A., Rossello, J., de Miguel, P., Nadal, M., \& Munar, E. (2014). Cognitive control and unusual decisions about beauty: an fMRI study. Front Hum Neurosci, 8, 520. https://doi.org/10.3389/fnhum. 2014.00520

Fox, P. T., Lancaster, J. L., Laird, A. R., \& Eickhoff, S. B. (2014). Metaanalysis in human neuroimaging: computational modeling of largescale databases. Annu Rev Neurosci, 37(1), 409-434. https://doi.org/ 10.1146/annurev-neuro-062012-170320

Funayama, R., Sugiura, M., Sassa, Y., Jeong, H., Wakusawa, K., Horie, K., ... Kawashima, R. (2012). Neural bases of human mate choice: Multiple value dimensions, sex difference, and self-assessment system. Soc Neurosci, 7(1), 59-73. https://doi.org/10.1080/17470919. 2011.580120

Germine, L., Russell, R., Bronstad, P. M., Blokland, Gabriëlla A. M., Smoller, Jordan W., Kwok, H., ... Wilmer, Jeremy B. (2015). Individual Aesthetic Preferences for Faces Are Shaped Mostly by Environments, Not Genes. Curr Biol, 25(20), 2684-2689. https:// doi.org/10.1016/j.cub.2015.08.048

Haber, S. N., \& Knutson, B. (2010). The Reward Circuit: Linking Primate Anatomy and $\mathrm{Human}$ Imaging. Neuropsychopharmacology, 35(1), 4-26. https://doi.org/10.1038/ npp.2009.129

Hahn, A. C., \& Perrett, D. I. (2014). Neural and behavioral responses to attractiveness in adult and infant faces. Neurosci Biobehav Rev, 46, Part 4(0), 591-603. https://doi.org/10.1016/j.neubiorev.2014.08.015

Harvey, A. H., Kirk, U., Denfield, G. H., \& Montague, P. R. (2010). Monetary Favors and Their Influence on Neural Responses and Revealed Preference. The Journal of Neuroscience, 30(28), 95979602. https://doi.org/10.1523/jneurosci.1086-10.2010

Hekkert, P., \& Wieringen, P. C. W. V. (1996). Beauty in the Eye of Expert and Nonexpert Beholders: A Study in the Appraisal of Art. Am J Psychol, 109(3), 389-407. https://doi.org/10.2307/1423013 
Hönekopp, J. (2006). Once more: Is beauty in the eye of the beholder? Relative contributions of private and shared taste to judgments of facial attractiveness. J Exp Psychol Hum Percept Perform, 32(2), 199-209. https://doi.org/10.1037/0096-1523.32.2.199

Hu, C., Di, X., Eickhoff, S. B., Zhang, M., Peng, K., Guo, H., \& Sui, J. (2016). Distinct and common aspects of physical and psychological self-representation in the brain: A meta-analysis of self-bias in facial and self-referential judgements. Neuroscience \& Biobehavioral Reviews, 61, 197-207. https://doi.org/10.1016/j.neubiorev.2015. 12.003

Hu, C., Di, X., Li, J., Sui, J., \& Peng, K. (2015). Meta-analysis of Neuroimaging Studies (in Chinese). Advances in Psychological Science, 23(7), 1118-1129. https://doi.org/10.3724/sp.j.1042.2015. 01118

Hu, C.-P., Jiang, X., Jeffrey, R., \& Zuo, X.-N. (2018). Open Science as a Better Gatekeeper for Science and Society: A Perspective from Neurolaw. Science Bulletin, 63(23), 1529-1531. https://doi.org/10. 1016/j.scib.2018.11.015

Huang, M., Bridge, H., Kemp, M. J., \& Parker, A. J. (2011). Human cortical activity evoked by the assignment of authenticity when viewing works of art. Frontiers in Human Neuroscience, 5. https:// doi.org/10.3389/fnhum.2011.00134

Iaria, G., Fox, C. J., Waite, C. T., Aharon, I., \& Barton, J. J. S. (2008). The contribution of the fusiform gyrus and superior temporal sulcus in processing facial attractiveness: Neuropsychological and neuroimaging evidence. Neuroscience, 155(2), 409-422. https://doi.org/10. 1016/j.neuroscience.2008.05.046

Ishizu, T., \& Zeki, S. (2011). Toward A Brain-Based Theory of Beauty. PLOS ONE, 6(7), e21852. https://doi.org/10.1371/journal.pone. 0021852

Ishizu, T., \& Zeki, S. (2013). The brain's specialized systems for aesthetic and perceptual judgment. Eur J Neurosci, 37(9), 1413-1420. https:// doi.org/10.1111/ejn.12135

Ito, A., Abe, N., Kawachi, Y., Kawasaki, I., Ueno, A., Yoshida, K., ... Fujii, T. (2015). Distinct neural correlates of the preference-related valuation of supraliminally and subliminally presented faces. Hum Brain Mapp, n/a-n/a. https://doi.org/10.1002/hbm.22813

Ito, A., Fujii, T., Abe, N., Kawasaki, I., Hayashi, A., Ueno, A., ... Mori, E. (2016). Gender differences in ventromedial prefrontal cortex activity associated with valuation of faces. Neuroscience, 328, 194200. https://doi.org/10.1016/j.neuroscience.2016.04.047

Ito, T., Wu, D. A., Marutani, T., Yamamoto, M., Suzuki, H., Shimojo, S., \& Matsuda, T. (2014). Changing the mind? Not really-activity and connectivity in the caudate correlates with changes of choice. Soc Cogn Affect Neurosci, 9(10), 1546-1551. https://doi.org/10.1093/ scan $/$ nst147

Jacobs, R. H., Renken, R., \& Cornelissen, F. W. (2012). Neural correlates of visual aesthetics-beauty as the coalescence of stimulus and internal state. Plos One, 7(2), e31248. https://doi.org/10.1371/journal. pone. 0031248

Jacobsen, T., Schubotz, R. I., Hofel, L., \& Cramon, D. Y. (2006). Brain correlates of aesthetic judgment of beauty. Neuroimage, 29(1), 276285. https://doi.org/10.1016/j.neuroimage.2005.07.010

Jennings, R., \& Horn, J. (2012). Publication bias in neuroimaging research: Implications for meta-analyses. Neuroinformatics, 10(1), 67-80. https://doi.org/10.1007/s12021-011-9125-y

Kalisch, R., Korenfeld, E., Stephan, K. E., Weiskopf, N., Seymour, B., \& Dolan, R. J. (2006). Context-Dependent Human Extinction Memory Is Mediated by a Ventromedial Prefrontal and Hippocampal Network. J Neurosci, 26(37), 9503-9511. https://doi.org/10.1523/ jneurosci.2021-06.2006

Kampe, K. K., Frith, C. D., Dolan, R. J., \& Frith, U. (2001). Reward value of attractiveness and gaze. Nature, 413(6856), 589. https://doi.org/ $10.1038 / 35098149$
Kawabata, H., \& Zeki, S. (2004). Neural Correlates of Beauty. $J$ Neurophysiol, 91(4), 1699-1705. https://doi.org/10.1152/jn.00696. 2003

Kedia, G., Mussweiler, T., Mullins, P., \& Linden, D. E. J. (2014). The neural correlates of beauty comparison. Soc Cogn Affect Neurosci, 9(5), 681-688. https://doi.org/10.1093/scan/nst026

Kesner, L., Grygarova, D., Fajnerova, I., Lukavsky, J., Nekovarova, T., Tintera, J., ... Horacek, J. (2018). Perception of direct vs. averted gaze in portrait paintings: An fMRI and eye-tracking study. Brain Cogn, 125, 88-99. https://doi.org/10.1016/j.bandc.2018.06.004

Kim, H., Adolphs, R., O'Doherty, J. P., \& Shimojo, S. (2007). Temporal isolation of neural processes underlying face preference decisions. Proc Natl Acad Sci USA, 104(46), 18253-18258. https://doi.org/10. 1073/pnas.0703101104

Kirk, U. (2008). The Neural Basis of Object-Context Relationships on Aesthetic Judgment. PLoS ONE, 3(11), e3754. https://doi.org/10. 1371/journal.pone.0003754

Kirk, U., Skov, M., Christensen, M. S., \& Nygaard, N. (2009). Brain correlates of aesthetic expertise: A parametric fMRI study. Brain Cogn, 69(2), 306-315. https://doi.org/10.1016/j.bandc.2008.08.004

Kirk, U., Skov, M., Hulme, O., Christensen, M. S., \& Zeki, S. (2009). Modulation of aesthetic value by semantic context: An fMRI study. NeuroImage, 44(3), 1125-1132. https://doi.org/10.1016/j. neuroimage.2008.10.009

Kirsch, L. P., Urgesi, C., \& Cross, E. S. (2016). The Shaping and Reshaping of the Aesthetic Brain: Emerging Perspectives on the Neurobiology of Embodied Aesthetics. Neurosci Biobehav Rev, 62, 56-68. https://doi.org/10.1016/j.neubiorev.2015.12.005

Kocsor, F., Feldmann, A., Bereczkei, T., \& Kállai, J. (2013). Assessing facial attractiveness: individual decisions and evolutionary constraints. Socioaffect Neurosci Psychol, 3, 21432. https://doi.org/10. 3402/snp.v3i0.21432

Kringelbach, M. L., \& Berridge, K. C. (2009). Towards a functional neuroanatomy of pleasure and happiness. Trends in Cognitive Sciences, 13(11), 479-487. https://doi.org/10.1016/j.tics.2009.08. 006

Lacey, S., Hagtvedt, H., Patrick, V. M., Anderson, A., Stilla, R., Deshpande, G., ... Sathian, K. (2011). Art for reward's sake: Visual art recruits the ventral striatum. NeuroImage, 55(1), 420433. https://doi.org/10.1016/j.neuroimage.2010.11.027

Laird, A. R., Eickhoff, S., Fox, P. M., Uecker, A., Ray, K., Saenz, J., ... Fox, P. T. (2011). The BrainMap strategy for standardization, sharing, and meta-analysis of neuroimaging data. BMC Res Notes, 4(1), 349. https://doi.org/10.1186/1756-0500-4-349

Laird, A. R., Eickhoff, S. B., Kurth, F., Fox, P. M., Uecker, A. M., Turner, J. A., ... Fox, P. T. (2009). ALE meta-analysis workflows via the BrainMap database: progress towards a probabilistic functional brain atlas. Front Neuroinform, 3, 23. https://doi.org/10.3389/ neuro.11.023.2009

Laird, A. R., Lancaster, J. L., \& Fox, P. T. (2009). Lost in localization? The focus is meta-analysis. NeuroImage, 48(1), 18-20. https://doi. org/10.1016/j.neuroimage.2009.06.047

Lancaster, J. L., Tordesillas-Gutiérrez, D., Martinez, M., Salinas, F., Evans, A., Zilles, K., ... Fox, P. T. (2007). Bias between MNI and Talairach coordinates analyzed using the ICBM-152 brain template. Hum Brain Mapp, 28(11), 1194-1205. https://doi.org/10.1002/hbm. 20345

Lebreton, M., Jorge, S., Michel, V., Thirion, B., \& Pessiglione, M. (2009). An Automatic Valuation System in the Human Brain: Evidence from Functional Neuroimaging. Neuron, 64(3), 431-439. https://doi.org/10.1016/j.neuron.2009.09.040

Leder, H., Goller, J., Rigotti, T., \& Forster, M. (2016). Private and Shared Taste in Art and Face Appreciation. Front Hum Neurosci, 10(155). https://doi.org/10.3389/fnhum.2016.00155

Leder, H., \& Nadal, M. (2014). Ten years of a model of aesthetic appreciation and aesthetic judgments : The aesthetic episode - 
Developments and challenges in empirical aesthetics. Brit J Psychol, 105(4), 443-464. https://doi.org/10.1111/bjop.12084

Levy, D. J., \& Glimcher, P. W. (2012). The root of all value: a neural common currency for choice. Current Opinion in Neurobiology, 22(6), 1027-1038. https://doi.org/10.1016/j.conb.2012.06.001

Liang, X., Zebrowitz, L. A., \& Zhang, Y. (2010). Neural activation in the "reward circuit" shows a nonlinear response to facial attractiveness. Soc Neurosci, 5(3), 320-334. https://doi.org/10.1080/ 17470911003619916

Liberati, A., Altman, D. G., Tetzlaff, J., Mulrow, C., Gøtzsche, P. C., Ioannidis, J. P. A., ... Moher, D. (2009). The PRISMA Statement for Reporting Systematic Reviews and Meta-Analyses of Studies That Evaluate Health Care Interventions: Explanation and Elaboration. PLoS Med, 6(7), e1000100. https://doi.org/10.1371/ journal.pmed.1000100

Little, A. C., Jones, B. C., \& DeBruine, L. M. (2011). Facial attractiveness: evolutionary based research. Philos T Roy Soc B, 366(1571), 1638-1659. https://doi.org/10.1098/rstb.2010.0404

Liu, X., Hairston, J., Schrier, M., \& Fan, J. (2011). Common and distinct networks underlying reward valence and processing stages: A metaanalysis of functional neuroimaging studies. Neuroscience \& Biobehavioral Reviews, 35(5), 1219-1236. https://doi.org/10.1016/ j.neubiorev.2010.12.012

Lutz, A., Nassehi, A., Bao, Y., Pöppel, E., Sztrókay, A., Reiser, M., ... Gutyrchik, E. (2013). Neurocognitive processing of body representations in artistic and photographic images. NeuroImage, 66(0), 288292. https://doi.org/10.1016/j.neuroimage.2012.10.067

Marr, D. (1982/2010). Vision: A computational investigation into the human representation and processing of visual information. Cambridge, MA: The MIT Press.

Martín-Loeches, M., Hernández-Tamames, J. A., Martín, A., \& Urrutia, M. (2014). Beauty and ugliness in the bodies and faces of others: An fmri study of person aesthetic judgement. Neuroscience, 277, 486497. https://doi.org/10.1016/j.neuroscience.2014.07.040

McGlone, F., Österbauer, R. A., Demattè, M., \& Spence, C. (2013). The crossmodal influence of odor hedonics on facial attractiveness: Behavioural and fMRI measures. In F. Signorelli \& D. Chirchiglia (Eds.), Functional Brain Mapping and the Endeavor to Understand the Working Brain: InTech.

Mende-Siedlecki, P., Said, C. P., \& Todorov, A. (2013). The social evaluation of faces: a meta-analysis of functional neuroimaging studies. Soc Cogn Affect Neurosci, 8(3), 285-299. https://doi.org/10.1093/ scan $/ \mathrm{nsr} 090$

Miura, N., Sugiura, M., Takahashi, M., Sassa, Y., Miyamoto, A., Sato, S., ... Kawashima, R. (2010). Effect of motion smoothness on brain activity while observing a dance: An fMRI study using a humanoid robot. Soc Neurosci, 5(1), 40-58. https://doi.org/10.1080/ 17470910903083256

Mizokami, Y., Terao, T., Hatano, K., Hoaki, N., Kohno, K., Araki, Y., ... Kochiyama, T. (2014). Difference in brain activations during appreciating paintings and photographic analogs. Front Hum Neurosci, 8 , 478. https://doi.org/10.3389/fnhum.2014.00478

Müller, V. I., Cieslik, E. C., Laird, A. R., Fox, P. T., Radua, J., MataixCols, D., ... Eickhoff, S. B. (2018). Ten simple rules for neuroimaging meta-analysis. Neuroscience \& Biobehavioral Reviews, 84, 151-161. https://doi.org/10.1016/j.neubiorev.2017.11.012

Munafò, M. R., Nosek, B. A., Bishop, D. V. M., Button, K. S., Chambers, C. D., Percie du Sert, N., ... Ioannidis, J. P. A. (2017). A manifesto for reproducible science. Nat Hum Behav, 1(1), 0021. https://doi. org/10.1038/s41562-016-0021

Nadal, M., Munar, E., Cap, Miquel, ngel, Rossell, ... Cela-Conde, C. J. (2008). Towards a framework for the study of the neural correlates of aesthetic preference. Spatial Vision, 21(3-5), 379-396. https://doi. org/10.1163/156856808784532653
Nadal, M., \& Skov, M. (2018). The pleasure of art as a matter of fact. Proceedings of the Royal Society B: Biological Sciences, 285(1875), 20172252. https://doi.org/10.1098/rspb.2017.2252

Nakamura, K., Kawashima, R., Nagumo, S., Ito, K., Sugiura, M., Kato, T., ... Kojima, S. (1998). Neuroanatomical correlates of the assessment of facial attractiveness. NeuroReport, 9(4), 753-757.

Nichols, T. E., Brett, M., Andersson, J., Wager, T., \& Poline, J.-B. (2005). Valid conjunction inference with the minimum statistic. NeuroImage, 25(3), 653-660. https://doi.org/10.1016/j.neuroimage. 2004.12.005

Northoff, G., Heinzel, A., de Greck, M., Bermpohl, F., Dobrowolny, H., \& Panksepp, J. (2006). Self-referential processing in our brain-A meta-analysis of imaging studies on the self. NeuroImage, 31(1), 440-457. https://doi.org/10.1016/j.neuroimage.2005.12.002

O’Doherty, J., Winston, J., Critchley, H., Perrett, D., Burt, D. M., \& Dolan, R. J. (2003). Beauty in a smile: the role of medial orbitofrontal cortex in facial attractiveness. Neuropsychologia, 41(2), 147-155. https://doi.org/10.1016/S0028-3932(02)00145-8

Parkinson, C., Liu, S., \& Wheatley, T. (2014). A Common Cortical Metric for Spatial, Temporal, and Social Distance. J Neurosci, 34(5), 1979-1987. https://doi.org/10.1523/jneurosci.2159-13.2014

Pearce, M. T., Zaidel, D. W., Vartanian, O., Skov, M., Leder, H., Chatterjee, A., \& Nadal, M. (2016). Neuroaesthetics: The Cognitive Neuroscience of Aesthetic Experience. Perspect Psychol Sci, 11(2), 265-279. https://doi.org/10.1177/1745691615621274

Pegors, T. K., Kable, J. W., Chatterjee, A., \& Epstein, R. A. (2015). Common and Unique Representations in $\mathrm{pFC}$ for Face and Place Attractiveness. J Cogn Neurosci, 27(5), 959-973. https://doi.org/10. 1162/jocn_a_00777

Poldrack, R. A., Baker, C. I., Durnez, J., Gorgolewski, K. J., Matthews, P. M., Munafo, M. R., ... Yarkoni, T. (2017). Scanning the horizon: towards transparent and reproducible neuroimaging research. Nat Rev Neurosci, 18(2), 115-126. https://doi.org/10.1038/nrn.2016.167

Rottschy, C., Langner, R., Dogan, I., Reetz, K., Laird, A. R., Schulz, J. B., ... Eickhoff, S. B. (2012). Modelling neural correlates of working memory: A coordinate-based meta-analysis. NeuroImage, 60(1), 830-846. https://doi.org/10.1016/j.neuroimage.2011.11.050

Roy, M., Shohamy, D., \& Wager, T. D. (2012). Ventromedial prefrontalsubcortical systems and the generation of affective meaning. Trends Cogn Sci, 16(3), 147-156. https://doi.org/10.1016/j.tics.2012.01. 005

Salimi-Khorshidi, G., Smith, S. M., Keltner, J. R., Wager, T. D., \& Nichols, T. E. (2009). Meta-analysis of neuroimaging data: A comparison of image-based and coordinate-based pooling of studies. NeuroImage, 45(3), 810-823. https://doi.org/10.1016/j.neuroimage. 2008.12.039

Schönbrodt, F. D., Maier, M., Heene, M., \& Zehetleitner, M. (2015). Voluntary commitment to research transparency. Retrieved from http://www.researchtransparency.org/

Sescousse, G., Caldú, X., Segura, B., \& Dreher, J.-C. (2013). Processing of primary and secondary rewards: A quantitative meta-analysis and review of human functional neuroimaging studies. Neurosci Biobehav Rev, 37(4), 681-696. https://doi.org/10.1016/j.neubiorev. 2013.02.002

Shen, H., Chau, D. K., Su, J., Zeng, L. L., Jiang, W., He, J., ... Hu, D. (2016). Brain responses to facial attractiveness induced by facial proportions: evidence from an fMRI study. Sci Rep, 6, 35905. https://doi.org/10.1038/srep35905

Silveira, S., Fehse, K., Vedder, A., Elvers, K., \& Hennig-Fast, K. (2015). Is it the picture or is it the frame? An fMRI study on the neurobiology of framing effects. Front Hum Neurosci, 9, 528. https://doi.org/ 10.3389/fnhum.2015.00528

Silveira, S., Graupmann, V., Agthe, M., Gutyrchik, E., Blautzik, J., Demirçapa, I., ... Hennig-Fast, K. (2014). Existential neuroscience: effects of mortality salience on the neurocognitive processing of 
attractive opposite-sex faces. Soc Cogn Affect Neurosci, 9(10), 1601-1607. https://doi.org/10.1093/scan/nst157

Silveira, S., Graupmann, V., Frey, D., Blautzik, J., Meindl, T., Reiser, M., ... Gutyrchik, E. (2012). Matching reality in the arts: Self-referential neural processing of naturalistic compared to surrealistic images. Perception, 41(5), 569-576.

Silveira, S., Gutyrchik, E., Wetherell, G., Bao, Y., Poeppel, E., Blautzik, J., ... Graupmann, V. (2015). Ceci n'est pas la mort: Evidence for the recruitment of self-reference from surrealistic art under mortality salience. European Journal of Social Psychology, 45(2), 255-266. https://doi.org/10.1002/ejsp.2076

Simmons, J. P., Nelson, L. D., \& Simonsohn, U. (2011). False-positive psychology: Undisclosed flexibility in data collection and analysis allows presenting anything as significant. Psychol Sci, 22(11), 1359-1366. https://doi.org/10.1177/0956797611417632

Skov, M. (2019). Aesthetic Appreciation: The View From Neuroimaging. Empirical Studies of the Arts, 37(2), 220-248. https://doi.org/10.1177/0276237419839257

Skov, M., \& Nadal, M. (2018). Art is not special: an assault on the last lines of defense against the naturalization of the human mind. Reviews in the Neurosciences, 29(6), 699. https://doi.org/10.1515/ revneuro-2017-0085

Skov, M., \& Nadal, M. (2020). A Farewell to Art: Aesthetics as a Topic in Psychology and Neuroscience. Perspect Psychol Sci. https://doi.org/ 10.1177/1745691619897963

Smith, D. V., Clithero, J. A., Boltuck, S. E., \& Huettel, S. A. (2014). Functional connectivity with ventromedial prefrontal cortex reflects subjective value for social rewards. Soc Cogn Affect Neurosci, 9(12), 2017-2025. https://doi.org/10.1093/scan/nsu005

Smith, D. V., Hayden, B. Y., Truong, T. K., Song, A. W., Platt, M. L., \& Huettel, S. A. (2010). Distinct value signals in anterior and posterior ventromedial prefrontal cortex. J Neurosci, 30(7), 2490-2495. https://doi.org/10.1523/jneurosci.3319-09.2010

Sui, J., Liu, M., Mevorach, C., \& Humphreys, G. W. (2015). The Salient Self: The Left Intraparietal Sulcus Responds to Social as Well as Perceptual-Salience After Self-Association. Cereb Cortex, 25(4), 1060-1068. https://doi.org/10.1093/cercor/bht302

Thakral, P. P., Moo, L. R., \& Slotnick, S. D. (2012). A neural mechanism for aesthetic experience. NeuroReport, 23(5), 310-313. https://doi. org/10.1097/WNR.0b013e328351759f

Tsukiura, T., \& Cabeza, R. (2011). Remembering beauty: Roles of orbitofrontal and hippocampal regions in successful memory encoding of attractive faces. NeuroImage, 54(1), 653-660. https:// doi.org/10.1016/j.neuroimage.2010.07.046

Turk, D. J., Banfield, J. F., Walling, B. R., Heatherton, T. F., Grafton, S. T., Handy, T. C., ... Macrae, C. N. (2004). From facial cue to dinner for two: the neural substrates of personal choice. NeuroImage, 22(3), 1281-1290. https://doi.org/10.1016/j.neuroimage.2004.02. 037

Turkeltaub, P. E., Eden, G. F., Jones, K. M., \& Zeffiro, T. A. (2002). Meta-analysis of the functional neuroanatomy of single-word reading: method and validation. NeuroImage, 16(3), 765-780. https:// doi.org/10.1006/nimg.2002.1131

Turkeltaub, P. E., Eickhoff, S. B., Laird, A. R., Fox, M., Wiener, M., \& Fox, P. (2012). Minimizing within-experiment and within-group effects in activation likelihood estimation meta-analyses. Hum Brain Mapp, 33(1), 1-13. https://doi.org/10.1002/hbm.21186

Ueda, R., Ashida, H., Yanagisawa, K., \& Abe, N. (2016). The neural basis of individual differences in mate poaching. Soc Neurosci, 19. https://doi.org/10.1080/17470919.2016.1182065

Ueno, A., Ito, A., Kawasaki, I., Kawachi, Y., Yoshida, K., Murakami, Y., ... Fujii, T. (2014). Neural activity associated with enhanced facial attractiveness by cosmetics use. Neurosci Lett, 566, 142-146. https:// doi.org/10.1016/j.neulet.2014.02.047
Vartanian, O., \& Goel, V. (2004). Neuroanatomical correlates of aesthetic preference for paintings. NeuroReport, 15(5), 893-897.

Vartanian, O., Goel, V., Lam, E., Fisher, M., \& Granic, J. (2013). Middle temporal gyrus encodes individual differences in perceived facial attractiveness. Psychology of Aesthetics, Creativity, and the Arts, 7, 38-47. https://doi.org/10.1037/a0031591

Vartanian, O., Navarrete, G., Chatterjee, A., Fich, L. B., Leder, H., Modrono, C., ... Skov, M. (2013). Impact of contour on aesthetic judgments and approach-avoidance decisions in architecture. Proc Natl Acad Sci U S A, 110 Suppl 2, 10446-10453. https://doi.org/10. 1073/pnas. 1301227110

Vartanian, O., \& Skov, M. (2014). Neural correlates of viewing paintings: Evidence from a quantitative meta-analysis of functional magnetic resonance imaging data. Brain Cogn, 87(0), 52-56. https://doi.org/ 10.1016/j.bandc.2014.03.004

Vessel, E. A., Starr, G. G., \& Rubin, N. (2012). The Brain on Art: Intense Aesthetic Experience Activates the Default Mode Network. Front Hum Neurosci, 6. https://doi.org/10.3389/fnhum.2012.00066

Wager, T. D., Lindquist, M., \& Kaplan, L. (2007). Meta-analysis of functional neuroimaging data: current and future directions. Soc Cogn Affect Neurosci, 2(2), 150-158. https://doi.org/10.1093/scan/ nsm015

Wang, T., Mo, L., Mo, C., Tan, L. H., Cant, J. S., Zhong, L., \& Cupchik, G. (2015). Is Moral Beauty Different from Facial Beauty? Evidence from an fMRI Study. Soc Cogn Affect Neurosci, 10(6), 814-823. https://doi.org/10.1093/scan/nsu123

Wiesmann, M., \& Ishai, A. (2010). Training facilitates object recognition in cubist paintings. Frontiers in Human Neuroscience, 4. https://doi. org/10.3389/neuro.09.011.2010

Winston, J. S., O’Doherty, J., Kilner, J. M., Perrett, D. I., \& Dolan, R. J. (2007). Brain systems for assessing facial attractiveness. Neuropsychologia, 45(1), 195-206. https://doi.org/10.1016/j. neuropsychologia.2006.05.009

Xia, M., Wang, J., \& He, Y. (2013). BrainNet Viewer: A Network Visualization Tool for Human Brain Connectomics. PLoS One, 8(7), e68910. https://doi.org/10.1371/journal.pone.0068910

Yu, H., Zhou, Z., \& Zhou, X. (2013). The amygdalostriatal and corticostriatal effective connectivity in anticipation and evaluation of facial attractiveness. Brain Cogn, 82(3), 291-300. https://doi.org/ 10.1016/j.bandc.2013.04.011

Zaki, J., Schirmer, J., \& Mitchell, J. P. (2011). Social influence modulates the neural computation of value. Psychol Sci, 22(7), 894-900. https://doi.org/10.1177/0956797611411057

Zeki, S., Romaya, J. P., Benincasa, D. M. T., \& Atiyah, M. F. (2014). The experience of mathematical beauty and its neural correlates. Frontiers in Human Neuroscience, 8. https://doi.org/10.3389/ fnhum.2014.00068

Zhai, H., Zhang, W., \& Su, J. (2010). Functional MRI of the perception of facial attractiveness. Scientia Sinica Vitae, 40(06), 551-560. https:// doi.org/10.1360/052009-432

Zhang, W., He, X., Lai, S., Wan, J., Lai, S., Zhao, X., \& Li, D. (2017). Neural substrates of embodied natural beauty and social endowed beauty: An fMRI study. Scientific Reports, 7. https://doi.org/10. 1038/s41598-017-07608-8

Zhang, W., Lai, S., He, X., Zhao, X., \& Lai, S. (2016). Neural correlates for aesthetic appraisal of pictograph and its referent: An fMRI study. Behav Brain Res, 305, 229-238. https://doi.org/10.1016/j.bbr.2016. 02.029

Publisher's note Springer Nature remains neutral with regard to jurisdictional claims in published maps and institutional affiliations. 